INNOVATIONS IN PRIMARY CARE

\title{
Embedding an Immigration Legal Navigator in a Primary Care Clinic
}

\author{
Sarab Kimball, $M D^{1,4} \quad$ Nausheen Singh, $M S^{3}$ \\ Mebar Maju² \\ Lily Sonis, LCSW, MPH \\ 'Boston University School of Medicine, Boston, Massachusetts \\ ${ }^{2}$ UCLA Fielding School of Public Health, Los Angeles, California \\ ${ }^{3}$ Icahn School of Medicine at Mount Sinai, New York, New York \\ ${ }^{4}$ Immigrant and Refugee Health Program, Boston Medical Center, \\ Boston, Massachusetts
}

Ann Fam Med 2019;17:177. https://doi.org/10.1370/afm.2360.

\section{THE INNOVATION}

Immigration status functions as an independent social determinant of health. ${ }^{1}$ To address this issue, the Immigrant $\&$ Refugee Health Program (IRHP) hosted an AmeriCorps member whose role was to help patients navigate the complex immigration system through referrals to community immigration legal programs and by advocating for them during their interactions with the immigration legal process.

\section{WHO \& WHERE}

The Immigrant and Refugee Health Program (IRHP) is part of Boston University School of Medicine and Boston Medical Center. For this pilot, we collaborated with the New American Integration Program, an AmeriCorps training program focused on immigrant and refugee services in Boston that recruited potential navigators and offered basic training and support throughout the year. The navigator was selected with priority given to communication skills, prior patient experience, and independent problem-solving skills. For more information about IRHP, please contact Sarah.Kimball@bmc.org.

\section{HOW}

The IRHP collaborates with multiple community organizations and legal service providers, who refer patients to the clinic for medical and behavioral health services that address the particular challenges of immigrant patients. Most referrals to the navigator came from screening done by clinicians and

Conflicts of interest: authors report none.

\section{Corresponding author}

Sarah Kimball, MD

801 Massachusetts Avenue Crosstown Center

Boston University School of Medicine

Boston, MA 02118

Sarah.Kimball@bmc.org case managers during program intake. Patients were asked whether they had immigration legal needs during a social determinants of health screen. Those who screened positive for needing immigration legal support were referred by warm hand-off or electronic medical record messages to the navigator for further assessment. Fewer referrals were identified through other hospital programs, usually when a patient's immigration status creates issues of access to care. The navigator was embedded in the clinic alongside a case manager, allowing for continuous collaboration among clinicians through informal and formal consults.

During the program's first year, the navigator saw 271 patients with a variety of immigration concerns. Legal needs included support for asylum (35\%), green card access (21\%), citizenship (5.2\%), family reunification (4\%), medical deferred action (1.5\%), deportation defense $(0.7 \%)$, supportive documentation such as a forensic affidavit or a medical disability waiver for citizenship (22.5\%), and general immigration questions (10\%). Of 116 patients who needed suuportive documentation, $82.8 \%$ had it completed, and $17.2 \%$ were pending at year-end. Of 155 patients who requested help with immigration representation or other community immigration referrals, $100 \%$ were referred to community partners and, of those, 36.8\% secured an attorney. For further information on patient characteristics and referral needs and outcomes, see Supplemental Tables 1-3, at http://www.annfammed.org/ content/17/2/177/suppl/DC1).

\section{LEARNING}

With increasing concern that immigrant patients curb their use of health care services out of fear of discrimination or legal repercussions, ${ }^{2}$ addressing their legal concerns and reinforcing confidentiality becomes critical to establishing trust in the medical system. By embedding immigration navigation services within the primary care clinic, patients were able to secure supportive documentation, immigration representation, or both. Despite the high need identified in clinic, our navigator was sometimes unable to find adequate affordable immigration representation, particularly for asylum-seekers, even when maximizing community resources, which speaks to the need to bolster community legal resources. This pilot intervention demonstrates the need for immigration-related services in primary care settings that serve high numbers of immigrants.

For author affiliations, supplemental tables, funding support, acknowledgments, and key words, see http://www. AnnFamMed. org/content/17/2/177/suppl/DC1/. 